\title{
Effect of socioeconomic status as measured by education level on survival in breast cancer clinical trials
}

\author{
James E. Herndon II ${ }^{*}$, Alice B. Kornblith ${ }^{2}$, Jimmie C. Holland ${ }^{3}$ and Electra D. Paskett ${ }^{4}$ \\ 'Department of Biostatistics \& Bioinformatics, Duke University Medical Center, Durham, NC, USA \\ ${ }^{2}$ Dana Farber Cancer Institute, Boston, MA, USA \\ ${ }^{3}$ Memorial Sloan-Kettering Cancer Center, New York, NY, USA \\ ${ }^{4}$ College of Medicine and Comprehensive Cancer Center, The Ohio State University, Columbus, OH, USA
}

*Correspondence to: Department of Biostatistics \& Bioinformatics, Hock Plaza, Suite 802, Duke University Medical Center, Box 2717, Durham, NC 27710, USA. E-mail: james. herndon@duke.edu
Received: 6 June 2011

Revised: 5 October 2011

Accepted: 5 October 2011

\begin{abstract}
Objectives: This paper aims to investigate the effect of socioeconomic status, as measured by education, on the survival of breast cancer patients treated on 10 studies conducted by the Cancer and Leukemia Group B.

Methods: Sociodemographic data, including education, were reported by the patient at trial enrollment. Cox proportional hazards model stratified by treatment arm/study was used to examine the effect of education on survival among patients with early stage and metastatic breast cancer, after adjustment for known prognostic factors.

Results: The patient population included 1020 patients with metastatic disease and 5146 patients with early stage disease. Among metastatic patients, factors associated with poorer survival in the final multivariable model included African American race, never married, negative estrogen receptor status, prior hormonal therapy, visceral involvement, and bone involvement. Among early stage patients, significant factors associated with poorer survival included African American race, separated/widowed, post/perimenopausal, negative/unknown estrogen receptor status, negative progesterone receptor status, $>4$ positive nodes, tumor diameter $>2 \mathrm{~cm}$, and education. Having not completed high school was associated with poorer survival among early stage patients. Among metastatic patients, non-African American women who lacked a high school degree had poorer survival than other non-African American women, and African American women who lacked a high school education had better survival than educated African American women.

Conclusions: Having less than a high school education is a risk factor for death among patients with early stage breast cancer who participated in a clinical trial, with its impact among metastatic patients being less clear. Post-trial survivorship plans need to focus on women with low social status, as measured by education.

Copyright $\odot 2011$ John Wiley \& Sons, Ltd.
\end{abstract}

Keywords: breast cancer; oncology; education; survival; SES

\section{Introduction}

The relationship between socioeconomic status (SES) and health/disease has been the focus of numerous investigations over the past 20-25 years. The basis for these investigations is often through the theoretical framework of social determinants of health $[1,2]$. Marmot, Wilkinson, and House reported the statistically significant effect of income and education on survival in the general population [1-5]. Marmot's explanation for this relationship in affluent countries, such as the USA, is that the relationship between income and survival is the result of relative differences in social participation and opportunity to control life circumstances [6]. Much of the literature focuses on income; however, Marmot argues that education may be a better indicator of factors linked to social position that are important to health and survival given that the effect of income on mortality is markedly reduced when education is included in predictive models [6].

In spite of the numerous published papers that have specifically examined the relationship between SES and cancer survival, questions persist because of inconsistent conclusions [7-32]. Possible explanations for this inconsistency include differences in the research question being asked (e.g., impact of SES on survival in the general population or impact in a clinical trial population), the patient population (e.g., homogeneous or heterogeneous histology or stage, as well as the national, racial, and ethnic composition), sample size or power considerations, the data source (e.g., census, regulatory, Surveillance, Epidemiology and End Results Program, clinical trial treatment trial, or patient reports), 
and the measure of SES (e.g., income, education, or occupation).

Such methodological differences are evident in research published in the past decade that has focused on the relationship between SES and survival among patients with breast cancer. Based upon education level reported to the French census, Menville reported that higher mortality observed among highly educated breast cancer patients had attenuated since the 1970s [29]. In contrast, Bouchardy [26], Dalton [27], and Thomson [28] reported that patients with lower SES had poorer prognosis. Bouchardy used patient-reported occupation to define SES among her population-based Swiss cohort that primarily had early stage breast cancer. Dalton linked Denmark's registry of patients who received adjuvant protocol treatment with an administrative database that contained each patient's education level. Thomson derived SES from Scotland's census data. Unlike multivariate analyses reported by Bouchardy and Dalton, the effect of SES disappeared in Thomson's study after adjustment for prognostic factors. Albano used data from the National Center for Health Statistics to show that the relative risk of death from breast cancer is highest among patients with 12 or fewer years of education [30]. Gordon used census-derived measures of education and income to show that low SES was associated with poorer survival among White, node-negative breast cancer clinical trial participants but not among African Americans [31,32].

Nearly 20 years ago, the Cancer and Leukemia Group B (CALGB), a national cooperative group funded by the National Cancer Institute explored the relationship between SES and survival of cancer patients enrolled on eight CALGB studies [33]. After adjustment for known prognostic factors including cancer type, performance status, age, and protocolspecific factors, analyses showed that clinical trial participants with low income or only a grade school education had poorer survival than patients with higher SES. This paper is part of a larger project to examine a large database of background forms that CALGB had routinely collected between 1990 and 1998, and to 'validate' findings of Cella [33] concerning the relationship of education and survival within larger, homogeneous cancer patient populations that participated in CALGB trials [34].

This paper focuses specifically upon the relationship between education and survival among patients with breast cancer who participated in one of 10 CALGBcoordinated clinical trials initiated between 1987 and 1998 (Table 1). Analyses assessed the effect of education on survival separately within early stage and metastatic patient subgroups. The strength of this research is that it uses a patient-reported measure of SES (education), explores the relationship between education and survival within one cancer type, and has power(i.e., sufficient patient numbers) to detect clinically important effect sizes within the unique context of clinical trials where initial therapeutic choices are not influenced by SES.

\section{Materials and methods}

\section{CALGB collection of socioeconomic data}

The CALGB Psychiatry Committee (later renamed the Psycho-Oncology Committee) piloted the collection of socioeconomic data from a background form [35] in the late 1980s and showed the feasibility of collecting such data for all variables except income. After completion of the feasibility study, CALGB initiated collection of background forms on all active studies. Patient-reported data collected at trial enrollment included education, race, and marital status. Education was presented as a multiple-choice question with the following options: grades 1-8, grades 9-11, high school graduate, some college, junior college degree, college degree, some postcollege, or advanced degree. Income was not collected because of collection difficulties encountered in the feasibility study. Survival and baseline clinical data were obtained from the CALGB database and merged with the background form. When these studies were initiated, CALGB required all patients to be followed until death.

\section{Patient population}

The analyses presented in this paper are based upon education and clinical data collected in 10 breast cancer studies coordinated by the CALGB. Studies are listed in Table 1, along with data concerning accrual, availability of education data and patient status (live/dead) at last follow-up. Study results, as well as details about treatment regimens administered, have been previously reported [36-47].

Submission of the background form that contained patient education data was required for all participants in six studies; exceptions included CALGB 8741, 9082, 9140, and 9840. For CALGB 8741 and 9082, this form was collected from a patient subgroup that participated in a separate quality of life companion study initiated after accrual to the treatment study commenced [36,38]. Enrollment to the companion of intergroup 9082 was also limited to participants from CALGB. For CALGB 9140, accrual was initiated before submission of the background form was required for all patients, as was the case for CALGB 9840, a study that included an unbalanced randomization.

\section{Power calculations}

A priori power calculations were generated to determine whether clinically meaningful effects would be detectable with available data if they existed. Cella reported that $31 \%$ of patients had only a grade school education and that their hazard ratio (HR) of death relative to patients with more than a grade school education was approximately 1.2 [33]. In the current dataset, 921 of 1020 metastatic breast cancer patients and 1881 of 5146 early stage patients are dead. Median follow-up time for early stage patients is 11.2 years. Among early stage and metastatic patients, $4 \%$ and $6 \%$ had $1-8$ years of education, respectively; 
Table I. Cancer and Leukemia Group B breast cancer studies from which patients were drawn

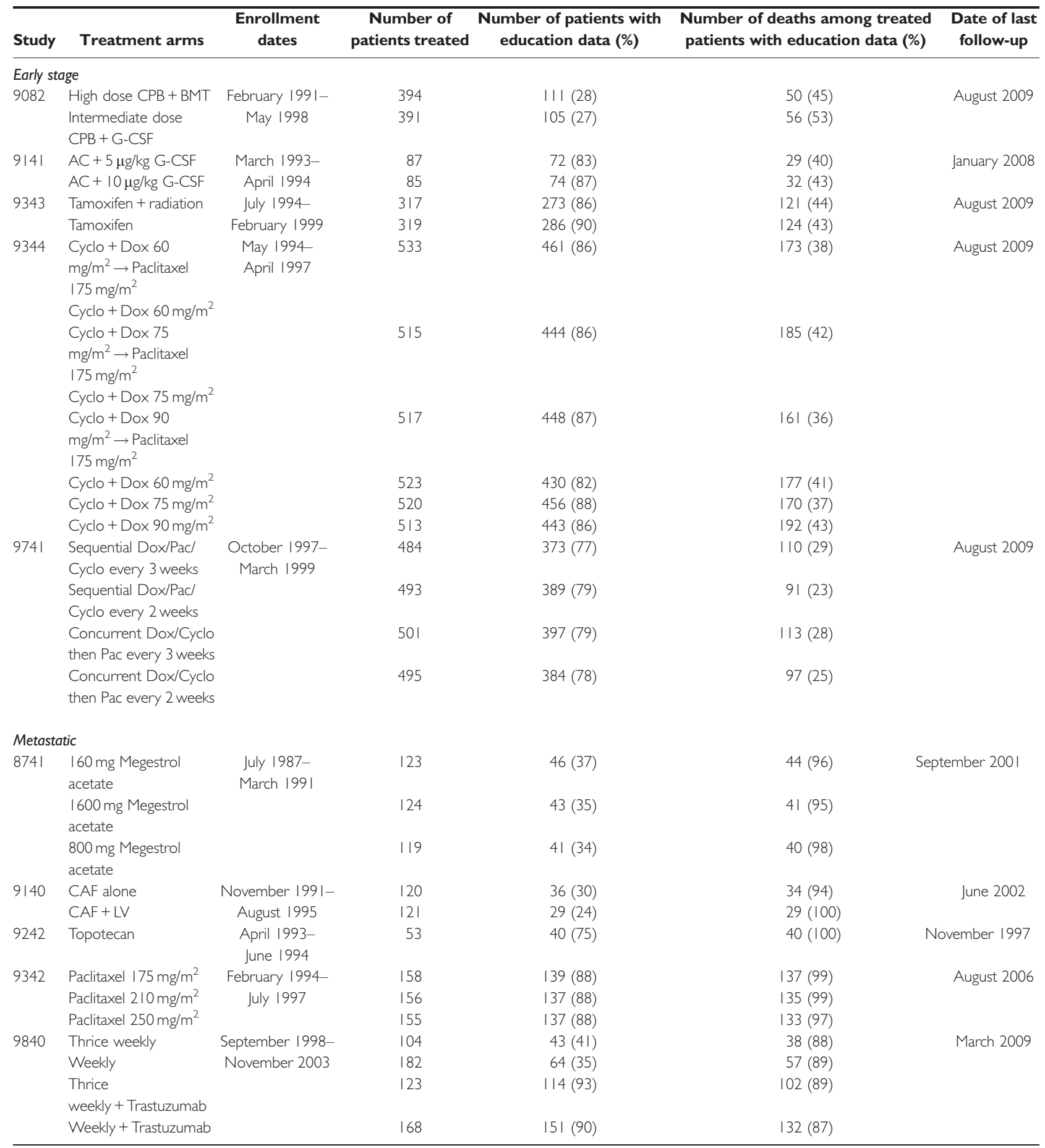

CPB, Cyclophosphamide, Cisplatin, and Carmustine; BMT, bone marrow transplant; AC, combination of Doxorubicin and Cyclophosphamide; G-CSF, granulocyte colony-stimulating factor; Dox, Doxorubicin; Cyclo, Cyclophosphamide; Pac, Paclitaxel; CAF, Cyclophosphamide, Doxorubicin, and Fluorouracil; LV, Leucovorin.

$11 \%$ and $19 \%$ had less than a high school education (Table 2). A two-tailed logrank test conducted within each subgroup to compare the survival of patients without and with a high school education had $80 \%$ power to detect an HR of 1.23 and 1.27, respectively, assuming $\alpha=0.05$ (48).

\section{Analytic methods}

To guard against possible bias associated with limiting analyses to only patients with education data, characteristics of patients (age, race) with and without education data were compared using chi-squared tests and $t$-tests.

Survival time, defined as the time between study enrollment and death, was censored for patients remaining alive at last follow-up. The Kaplan-Meier product limit estimator was used to describe the survival experience within patient subgroups defined by various prognostic factors and education levels [48]. Median survival estimates were generated using the estimator of Brookmeyer and Crowley [49]. The Cox 
Table 2. Characteristics of breast cancer patients stratified by disease status and survival rates

\begin{tabular}{|c|c|c|c|c|c|c|c|c|}
\hline Predictor & Subgroup & $N$ & $\%$ & $\begin{array}{c}\text { Number of } \\
\text { dead }\end{array}$ & $\begin{array}{l}\text { Hazard } \\
\text { ratio }\end{array}$ & $\begin{array}{l}95 \% \text { lower confidence } \\
\text { limit for hazard ratio }\end{array}$ & $\begin{array}{l}95 \% \text { upper confidence } \\
\text { limit for hazard ratio }\end{array}$ & p-value* \\
\hline \multicolumn{9}{|l|}{ Early stage patients } \\
\hline \multirow[t]{4}{*}{ Race } & White & 4358 & 85 & 1574 & Reference & & & \\
\hline & Black & 493 & 10 & 209 & 1.38 & 1.20 & 1.60 & \\
\hline & Hispanic & 177 & 3 & 59 & 1.13 & 0.87 & 1.47 & \\
\hline & Other & 118 & 2 & 39 & 1.21 & 0.65 & 2.26 & 0.0004 \\
\hline \multirow[t]{6}{*}{ Age group (years) } & $<30$ & 76 & 1 & 34 & Reference & & & \\
\hline & $30-39$ & 807 & 16 & 305 & 0.88 & 0.62 & 1.26 & \\
\hline & $40-49$ & 1784 & 35 & 554 & 0.69 & 0.49 & 0.98 & \\
\hline & $50-59$ & 1317 & 26 & 469 & 0.84 & 0.59 & 1.19 & \\
\hline & $60-69$ & 526 & 10 & 234 & 1.12 & 0.78 & 1.61 & \\
\hline & $70+$ & 636 & 12 & 285 & 1.42 & 0.90 & 2.25 & $<0.000$ I \\
\hline \multirow[t]{6}{*}{ Marital status } & Married & 3367 & 65 & 1156 & Reference & & & \\
\hline & Single & 421 & 8 & 152 & 1.15 & 0.97 & 1.36 & \\
\hline & Separated & 157 & 3 & 68 & 1.38 & 1.08 & 1.76 & \\
\hline & Divorced & 687 & 13 & 263 & 1.23 & 1.07 & 1.40 & \\
\hline & Widowed & 491 & 10 & 234 & 1.52 & 1.30 & 1.79 & \\
\hline & Unknown & 23 & $<1$ & 8 & 1.06 & 0.53 & 2.13 & $<0.000$ | \\
\hline \multirow[t]{3}{*}{ Menopausal status } & Premenopause & 2658 & 52 & 871 & Reference & & & \\
\hline & Post/perimenopuase & 2456 & 48 & 998 & 1.33 & 1.21 & 1.47 & \\
\hline & Unknown & 32 & I & 12 & 1.61 & 0.91 & 2.85 & $<0.000$ | \\
\hline \multirow[t]{3}{*}{ ER } & Negative & $174 \mid$ & 34 & 753 & Reference & & & \\
\hline & Positive & 3362 & 65 & 1109 & 0.61 & 0.55 & 0.67 & \\
\hline & Unknown & 43 & I & 19 & 0.92 & 0.58 & 1.46 & $<0.000$ | \\
\hline \multirow[t]{3}{*}{ PR } & Negative & 2039 & 40 & 858 & Reference & & & \\
\hline & Positive & 3038 & 59 & 997 & 0.65 & 0.59 & 0.71 & \\
\hline & Unknown & 69 & I & 26 & 0.75 & 0.51 & 1.11 & $<0.000$ | \\
\hline \multirow[t]{5}{*}{ Number of positive nodes } & 0 & 255 & 5 & 125 & Reference & & & \\
\hline & $1-3$ & 311 & 6 & 127 & 0.35 & 0.18 & 0.66 & \\
\hline & $4-9$ & 2235 & 43 & 564 & 0.58 & 0.30 & 1.10 & \\
\hline & $10+$ & 1629 & 32 & 658 & 1.08 & 0.56 & 2.07 & \\
\hline & Unknown & 716 & 14 & 407 & 1.31 & 1.02 & 1.68 & $<0.000$ | \\
\hline \multirow[t]{3}{*}{ Tumor size } & $\leq 2 \mathrm{~cm}$ & $174 \mid$ & 34 & 753 & Reference & & & \\
\hline & $>2 \mathrm{~cm}$ & 3362 & 65 & 1109 & 1.58 & 1.42 & 1.77 & \\
\hline & Unknown & 43 & । & 19 & 1.04 & 0.69 & 1.55 & $<0.000$ | \\
\hline \multirow[t]{8}{*}{ Education } & I-8 grades & 203 & 4 & 98 & Reference & & & \\
\hline & $9-11$ grades & 387 & 8 & 177 & 0.87 & 0.68 & 1.12 & \\
\hline & High school graduate & 1557 & 30 & 584 & 0.67 & 0.54 & 0.83 & \\
\hline & Some college & 1130 & 22 & 411 & 0.64 & 0.52 & 0.80 & \\
\hline & Junior college & 341 & 7 & 120 & 0.62 & 0.48 & 0.82 & \\
\hline & College & 766 & 15 & 252 & 0.56 & 0.45 & 0.72 & \\
\hline & Some post-college & 247 & 5 & 82 & 0.56 & 0.42 & 0.76 & \\
\hline & Advanced degree & 515 & 10 & 157 & 0.52 & 0.40 & 0.67 & $<0.000$ । \\
\hline \multicolumn{9}{|l|}{ Metastatic patients } \\
\hline Race & White & 793 & 78 & 748 & Reference & & & \\
\hline & Black & |7| & 17 & 164 & 1.37 & 1.15 & 1.62 & \\
\hline & Hispanic & 30 & 3 & 24 & 0.97 & 0.64 & 1.46 & \\
\hline & Other & 26 & 3 & 25 & 0.86 & 0.32 & 2.33 & 0.0075 \\
\hline Age group (years) & $<30$ & 8 & 1 & 8 & Reference & & & \\
\hline & $30-39$ & 68 & 7 & 65 & 0.79 & 0.37 & 1.69 & \\
\hline & $40-49$ & 212 & 21 & 192 & 0.66 & 0.32 & 1.36 & \\
\hline & $50-59$ & 330 & 32 & 308 & 0.66 & 0.32 & 1.36 & \\
\hline & $60-69$ & 277 & 27 & 268 & 0.69 & 0.34 & 1.42 & \\
\hline & $70+$ & 125 & 12 & 120 & 0.78 & 0.37 & 1.63 & 0.4572 \\
\hline Marital status & Married & 600 & 59 & 566 & Reference & & & \\
\hline & Single & 97 & 10 & 93 & 1.35 & 1.08 & 1.70 & \\
\hline & Separated & 41 & 4 & 36 & 0.94 & 0.67 & 1.32 & \\
\hline & Divorced & 149 & 15 & 140 & 1.09 & 0.91 & 1.32 & \\
\hline & Widowed & 128 & 13 & 121 & 1.04 & 0.85 & 1.27 & \\
\hline & Unknown & 5 & $<1$ & 5 & 0.69 & 0.28 & 1.69 & 0.1511 \\
\hline ECOG PS & 0 & 476 & 47 & 435 & Reference & & & \\
\hline & 1 & 463 & 45 & 445 & 1.38 & 1.20 & 1.58 & \\
\hline & 2 & 70 & 7 & 70 & 1.52 & 1.33 & 1.73 & \\
\hline & Unknown & 11 & 1 & 11 & 1.16 & 0.63 & 2.12 & $<0.000$ I \\
\hline Menopausal status & Premenopause & 171 & 17 & 154 & Reference & & & \\
\hline & Post/perimenopause & 836 & 82 & 794 & 1.12 & 0.93 & 1.33 & \\
\hline & Unknown & 13 & I & 13 & 1.45 & 0.81 & 2.61 & 0.3084 \\
\hline
\end{tabular}


Table 2. Continued

\begin{tabular}{|c|c|c|c|c|c|c|c|c|}
\hline Predictor & Subgroup & $N$ & $\%$ & $\begin{array}{c}\text { Number of } \\
\text { dead }\end{array}$ & $\begin{array}{c}\text { Hazard } \\
\text { ratio }\end{array}$ & $\begin{array}{l}95 \% \text { lower confidence } \\
\text { limit for hazard ratio }\end{array}$ & $\begin{array}{l}95 \% \text { upper confidence } \\
\text { limit for hazard ratio }\end{array}$ & p-value* \\
\hline \multirow[t]{3}{*}{ ER } & Negative & 366 & 36 & 344 & Reference & & & \\
\hline & Positive & 550 & 54 & 515 & 0.70 & 0.60 & 0.81 & \\
\hline & Unknown & 104 & 10 & 102 & 0.77 & 0.61 & 0.97 & $<0.000$ I \\
\hline \multirow[t]{3}{*}{ PR } & Negative & 433 & 42 & 403 & Reference & & & \\
\hline & Positive & 448 & 44 & 421 & 0.78 & 0.68 & 0.90 & \\
\hline & Unknown & 139 & 14 & 137 & 0.87 & 0.71 & 1.07 & 0.0030 \\
\hline \multirow[t]{3}{*}{ Prior hormonal therapy } & No & 429 & 42 & 396 & Reference & & & \\
\hline & Yes & 577 & 57 & 553 & 1.08 & 0.94 & 1.23 & \\
\hline & Unknown & 14 & । & 12 & 0.79 & 0.44 & 1.42 & 0.3521 \\
\hline \multirow[t]{3}{*}{ Prior chemotherapy } & No & 320 & 31 & 296 & Reference & & & \\
\hline & Yes & 679 & 67 & 646 & 1.07 & 0.91 & 1.25 & \\
\hline & Unknown & 21 & 2 & 19 & 1.20 & 0.74 & 1.94 & 0.6308 \\
\hline \multirow[t]{3}{*}{ Prior RT } & No & 429 & 42 & 396 & Reference & & & \\
\hline & Yes & 577 & 57 & 553 & 1.02 & 0.87 & 1.20 & \\
\hline & Unknown & 14 & । & 12 & 1.19 & 0.93 & 1.52 & 0.3165 \\
\hline \multirow[t]{2}{*}{ Visceral involvement } & No & 294 & 29 & 268 & Reference & & & \\
\hline & Yes & 726 & 71 & 693 & 1.33 & 1.15 & 1.54 & 0.0001 \\
\hline \multirow[t]{2}{*}{ Bone/marrow involvement } & No & 474 & 46 & 428 & Reference & & & \\
\hline & Yes & 546 & 54 & 533 & 1.30 & 1.14 & 1.48 & 0.0001 \\
\hline \multirow[t]{8}{*}{ Education } & 1-8 grades & 61 & 6 & 58 & Reference & & & \\
\hline & 9-1I grades & 133 & 13 & 130 & 1.19 & 0.86 & 1.63 & \\
\hline & High school graduate & 361 & 35 & 344 & 1.02 & 0.77 & 1.36 & \\
\hline & Some college & 191 & 19 & 175 & 0.95 & 0.70 & 1.29 & \\
\hline & Junior college & 44 & 4 & 41 & 0.89 & 0.59 & 1.34 & \\
\hline & College & 105 & 10 & 96 & 0.97 & 0.69 & 1.36 & \\
\hline & Some post-college & 54 & 5 & 51 & 0.96 & 0.66 & 1.41 & \\
\hline & Advanced degree & 71 & 7 & 66 & 0.91 & 0.63 & 1.31 & 0.6211 \\
\hline
\end{tabular}

PS was not collected in early stage studies.

Patients with NO M0 disease were elderly patients from Cancer and Leukemia Group B 9343.

*From logrank test without adjustment for other covariables.

ECOG PS, Eastern Cooperative Oncology Group Performance Status; ER, estrogen receptor; PR, progesterone receptor; RT, radiation therapy.

proportional hazards model stratified by treatment arm/ study was used to assess the relationship between survival and known prognostic factors listed in Table 2, as well as interactions of education with age and race [50,51]. A reference cell parameterization was used to model categorical variables in the Cox model with one category representing missing data. Analyses used backwards elimination to obtain a parsimonious multivariable clinical model predictive of survival, in which age was considered as an uncategorized predictor. Martingale and Schoenfeld residuals were used to assess the adequacy of the proportional hazards assumption [51]. Once a final multivariable clinical model was determined, factors describing the effect of education were added to the Cox model. Analyses were conducted separately among early stage and metastatic patient subgroups.

\section{Results}

The analyses described in this paper are based upon the experiences of all patients accrued to one of 10 breast cancer studies that provided education data (Table 1). These 6166 patients constituted $74 \%$ of the enrolled patients. A comparison of the characteristics of patients included and not included in these analyses showed no significant difference relative to age (data not shown). Among patients who had the opportunity to provide education data, the racial composition of the group of patients who did and did not provide education data did not significantly differ.

The study cohort included 5146 early stage patients and 1020 metastatic patients. The majority were White $(84 \%)$, and $52 \%$ were 50 years of age or older (Table 2). A greater proportion of metastatic patients were African American (17\% vs $10 \%), 50$ years of age or older $(72 \%$ vs $48 \%$ ), postmenopausal ( $82 \%$ vs $48 \%$ ), or had less than a high school education (19\% vs $11 \%)$ than that observed among early stage patients $(p<0.001$ for all comparisons). African American patients were less likely to be a high school graduate than non-African Americans $(72 \%$ vs $90 \% ; p<0.0001)$, as were older patients $(78 \%$ vs $90 \% ; p<0.0001)$ and separated/ widowed patients ( $72 \%$ vs $89 \% ; p<0.0001)$.

The relationship between education and survival is graphically summarized in Figures 1 and 2 for early stage and metastatic disease subgroups; associated statistics are provided in Table 2 . Within the early stage subgroup, education had a statistically significant effect on survival $(p<0.0001)$ with poorest prognosis being among patients with less than a high school education in comparison with patients who completed high school $(\mathrm{HR}=1.47 ; 95 \%$ CI: $1.29,1.68)$. Among patients with metastatic disease, survival of patients who did and did not complete high school was not significantly different $(p=0.095 ; \mathrm{HR}=1.15 ; 95 \%$ CI: $0.98,1.353)$. 


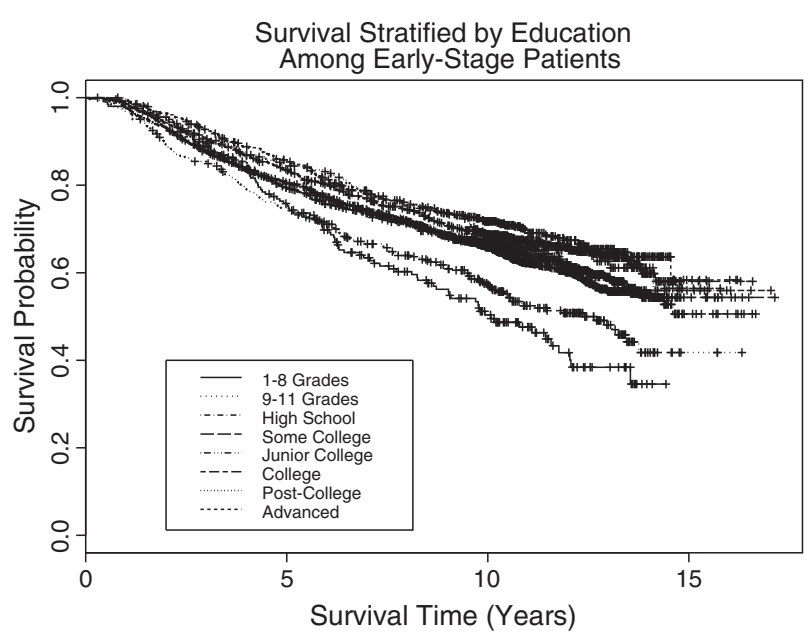

Figure I. Survival stratified by education among early stage patients

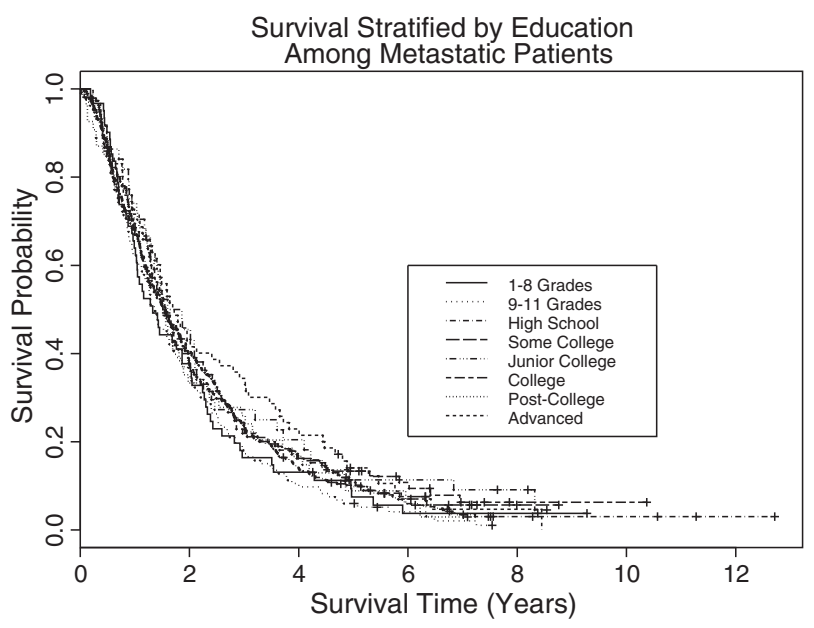

Figure 2. Survival stratified by education among metastatic patients

In addition to education, the following individual factors were significantly associated with better survival among early stage patients: non-African American race, married or single women, premenopausal status, estrogen receptor (ER) positive, progesterone receptor (PR) positive, one to three positive nodes, and tumor diameter $2 \mathrm{~cm}$ or less. Among patients with metastatic cancer, factors associated with better survival included non-African American race, performance status $(\mathrm{PS})=0$, ER positive, PR positive, no visceral involvement, and no bone involvement. These results are consistent with the literature concerning known prognostic factors for breast cancer.

Multivariable Cox regression analysis showed that after adjustment for known prognostic factors, early stage patients with less than a high school education were at greater risk of dying than patients who completed high school (Table 3; $p=0.0007 ; \mathrm{HR}=1.26$ ). African American women were at greater risk of dying than nonAfrican American women $(p=0.007 ; \mathrm{HR}=1.23)$, with no evidence that the effect differed among patients with and without a high school education $(p=0.453$; model not shown).
Table 3. Multivariable Cox models predictive of survival

\begin{tabular}{|c|c|c|c|c|}
\hline Parameter & $\begin{array}{c}\text { Hazard } \\
\text { ratio }\end{array}$ & $\begin{array}{l}95 \% \text { hazard } \\
\text { confidence }\end{array}$ & $\begin{array}{l}\text { Ratio } \\
\text { limits }\end{array}$ & $p$-value \\
\hline \multicolumn{5}{|l|}{ Model for early stage patients } \\
\hline African American & 1.226 & 1.057 & 1.421 & 0.0069 \\
\hline \multicolumn{5}{|l|}{ Marital status: } \\
\hline Separated versus married/single & 1.244 & 0.971 & 1.594 & 0.0838 \\
\hline Divorced versus married/single & 1.178 & 1.031 & 1.347 & 0.0161 \\
\hline Widowed versus married/single & 1.270 & 1.083 & 1.489 & 0.0032 \\
\hline Post/perimenopausal & 1.178 & 1.068 & 1.301 & 0.0011 \\
\hline ER positive/unknown & 0.669 & 0.591 & 0.756 & $<0.0001$ \\
\hline PR positive/unknown & 0.851 & 0.756 & 0.957 & 0.0071 \\
\hline \multicolumn{5}{|l|}{ Number of positive nodes } \\
\hline $4-9$ vs $0-3$ & 1.625 & 1.450 & 1.821 & $<0.0001$ \\
\hline $10+$ vs $0-3$ & 2.741 & 2.374 & 3.165 & $<0.0001$ \\
\hline Unknown vs $0-3$ & 1.394 & 1.091 & 1.780 & 0.0078 \\
\hline Tumor diameter $>2 \mathrm{~cm}$ & 1.392 & 1.250 & 1.552 & $<0.0001$ \\
\hline Education not high school graduate & 1.259 & 1.102 & 1.439 & 0.0007 \\
\hline \multicolumn{5}{|l|}{ Model for metastatic patients } \\
\hline African American & 1.531 & 1.240 & 1.890 & $<0.000$ I \\
\hline Single & 1.282 & 1.026 & 1.601 & 0.0291 \\
\hline \multicolumn{5}{|l|}{ Performance status } \\
\hline I vs 0/unknown & 1.289 & 1.121 & 1.482 & 0.0004 \\
\hline 2 vs 0/unknown & 1.424 & 1.245 & 1.629 & $<0.0001$ \\
\hline \multicolumn{5}{|l|}{ Estrogen receptor } \\
\hline Positive versus negative & 0.627 & 0.534 & 0.735 & $<0.000$ I \\
\hline Unknown versus negative & 0.689 & 0.544 & 0.874 & 0.0021 \\
\hline Prior hormonal therapy & 1.194 & 1.037 & 1.374 & 0.0134 \\
\hline Visceral involvement & 1.288 & 1.107 & 1.498 & 0.0011 \\
\hline Bone involvement & 1.319 & 1.145 & 1.519 & 0.0001 \\
\hline Education not high school graduate & 1.188 & 0.981 & 1.438 & 0.0779 \\
\hline $\begin{array}{l}\text { Not high school graduate among } \\
\text { African American }\end{array}$ & 0.669 & 0.455 & 0.981 & 0.0397 \\
\hline
\end{tabular}

A stratified Cox proportional hazards model with backwards elimination was used to generate these models.

Among metastatic breast cancer patients, multivariable analysis showed that the effect of having less than a high school education varied across racial groups $(p=0.040$; Table 3). The HR associated with having less than a high school education was 0.80 (95\%CI: $0.57,1.11)$ among African Americans and 1.19 (95\% CI: 0.98, 1.44) among non-African Americans. Of greater magnitude was the statistically significant HR for race: 1.53 (95\%CI: 1.24 , 1.89). A model without the interaction between race and education shows that the African American main effect was statistically significant $(p=0.001 ; \mathrm{HR}=1.35$; 95\%CI: $1.13,1.62$ ) and the education main effect was not $(p=0.442 ; \mathrm{HR}=1.07 ; 95 \% \mathrm{CI}: 0.90,1.26$; model not shown).

\section{Discussion}

Analyses hypothesized a priori that clinical trial participation with standardized treatment plans and rigorous patient follow-up would initially negate any potential effect of social class, as measured by education, on the hazard of dying, and that after completion of 'active' protocol treatment, the effect of education would emerge. This hypothesis implied that education would not have an impact upon the survival of metastatic patients, given that such patients are intensively followed until treatment failure and death, and that 
education would have an effect among early stage patients as they are less rigorously followed long-term after protocol treatment termination.

The hypothesis was substantiated with multivariable analyses among early stage patients where the lack of a high school education and African American race were associated with a greater hazard of dying. Hazard ratios for race and education are of similar magnitude, with no evidence of an inconsistent effect of education across racial groups.

Within the metastatic patient population, the relationship between education and survival is complicated by a statistically significant interaction that suggests that the effect of education on survival varies across racial groups. Within each racial group, the effect of education is not statistically significant. Among African Americans, the lack of high school education is associated with better survival $(\mathrm{HR}=0.8)$. However, among non-African Americans, the lack of a high school education is associated with poorer survival $(\mathrm{HR}=1.18)$, an effect that is opposite to that seen among African Americans. It is not clear whether the statistically significant interaction is a false positive result and an artifact of the non-significant effects of education that are in opposite directions, or whether this result is an indication that African American women with less education are tied into services that might support them more than less educated non-African American women. Regardless, survival of African Americans is poorer than that of non-African Americans $(\mathrm{HR}=1.53)$.

The fact that education had a statistically significant effect on survival among early stage patients that did not vary across racial groups is consistent with reports by Meara that there is a gap in life expectancy among women with low and high education regardless of race [52]. In contrast, among patients with metastatic disease, education did not have an effect on survival within racial subgroups.

This study is unique in that it focuses on the effect of education within a setting where initial therapeutic decisions are not influenced by SES. SES, however, may have resulted in observed differences in baseline characteristics of the early stage and metastatic subgroups due to influences of SES on stage at diagnosis [53-57] and access to clinical trials.

Commonly used 'area-wide measures' of socioeconomic data based upon census or administrative databases are unreliable as they classify all patients within a heterogeneous community as having the same SES, as measured by education or income [58]. Dale advocates use of SES measures obtained from each individual and argues that income and education data should be obtained with the recognition that other factors such as occupation might be needed to capture the full effect of SES [16]. Furthermore, Dale recommends that investigations focusing on SES and cancer survival should have adequate sample sizes to make scientifically and statistically sound inferences and that the investigations focus on specific cancer sites. With these criteria as benchmarks, the study described in this paper is reasonably well designed to investigate the relationship between SES and cancer survival in that SES, as measured by education, is available on the individual patient level, the sample size is large enough to assure statistically sound inferences, and a relatively homogeneous population, that is, one cancer site, has been studied. The inclusion of patient-reported income would have strengthened the study; however, such data were purposely not collected as previous pilot work had indicated that a large percentage of patients would not provide such data [35].

Given that race has been the focus of much of the published clinical literature concerning the effect of SES on survival, race was included in analyses as a potential confounder of the effect of education. The increased risk of death among African American women as shown in analyses is consistent with previous reports [58-60].

Both Albain [59] and Polite [60] have wrestled with the source of the race effect, whether it is biologically based or a result of SES. The provocative paper by Albain reports no racial effect on survival among patients with acute myelogenous leukemia, limited small cell lung cancer, advanced stage non-small cell lung cancer, multiple myeloma, adjuvant colon cancer, and advanced stage non-Hodgkin's lymphoma and a statistically significant negative effect of being African American on survival among sex-specific cancers (i.e., early stage breast cancer, advanced stage ovarian cancer, and advanced stage prostate cancer). The CALGB has reported similar observations for lung cancer $[34,61,62]$. The results presented in this paper complement the report by Albain as it has shown that the mortality rate associated with metastatic breast cancer is greatest among African American women. Albain concludes that tumor biology and inherited host factors contribute to differential survival outcomes by race in sex-specific malignancies.

Both race and education have been found to be independent predictors of survival among early stage breast cancer patients treated on CALGB clinical trials. Among patients with metastatic disease, race also has a significant effect on survival; however, education appears to have an effect on survival that is inconsistent across racial groups. We conjecture that education is a surrogate for social status, whereas race is a surrogate for both biological/genetic and social factors. Additional research is needed to substantiate such a statement and to gain a better understanding of the relationship between race, education, stage, clinical trial participation, and survival. An integral part of this additional research needs to be an examination of sociocultural and behavioral factors that contribute to long-term breast cancer survivors with low SES having poorer prognosis.

Regardless of the underlying mechanism for the associations between education and survival, it is clear that post-trial survivorship plans need to focus on women with low social status, as measured by education. Issues that need consideration include long-term compliance with hormone administration, management of comorbidities, cancer prevention, and detection. 


\section{Acknowledgements}

The research was supported, in part, by grants from the National Cancer Institute (CA31946) to the Cancer and Leukemia Group B (Richard L. Schilsky, MD, Chairman) and to the CALGB Statistical Center (Stephen George, PhD, CA33601). The authors were also supported by grants (Alice B. Kornblith, $\mathrm{PhD}$, CA32291; Jimmie C. Holland, MD, CA77651; Electra D. Paskett,

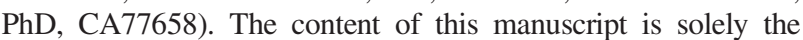
responsibility of the authors and does not necessarily represent the official views of the National Cancer Institute.

\section{References}

1. House JS, Landis KR, Umberson D. Social relationships and health. Science 1988;241:540-545.

2. Marmot M. Social determinants of health equalities. Lancet 2005;365:1099-1104.

3. Lynch JW, Smith GD, Kaplan GA et al. Income inequality and mortality: importance to health of individual income, psychosocial environment, or material conditions. BMJ 2000;320:1200-1204.

4. Marmot M, Ryff CD, Bumpass LL et al. Social inequalities in health: next questions and converging evidence. Soc Sci Med 1997;44(6):901-910.

5. Marmot M, Wilkinson RG. Psychosocial and material pathways in the relations between income and health: a response to Lynch et al. BMJ 2001;322:1233-1236.

6. Marmot M. The influence of income on health: views of an epidemiologist. Health Aff 2002;21(2):31-46.

7. Yabroff KR, Gordis L. Does stage at diagnosis influence the observed relationship between socioeconomic status and breast cancer incidence, case-fatality, and mortality? Soc Sci Med 2003;57:2265-2279.

8. Cross CK, Harris J, Recht A. Race, socioeconomic status, and breast carcinoma in the U.S.: what have we learned from clinical studies? Cancer 2001;95:1988-99.

9. Gorey KM, Kliewer E, Holowaty EJ et al. An international comparison of breast cancer survival: Winnipeg, Manitoba and Des Moines, Iowa metropolitan areas. Ann Epidemiol 2002;13:32-41.

10. Mariotto A, Capocaccia R, Verdecchia A et al. Projecting SEER cancer survival rates to the US: an ecological regression approach. Cancer Causes Control 2002;13:101-111.

11. Coleman MP, Babb P, Sloggett A et al. Socioeconomic inequalities in cancer survival in England and Wales. Cancer 2001;91:208-16.

12. Vigano A, Bruera E, Jhangri GS et al. Clinical survival predictors in patients with advanced cancer. Arch Intern Med 2000; 160:861-868.

13. Mackillop WJ, Zhang-Salomons J, Groome PA et al. Socioeconomic status and cancer survival in Ontario. JCO 1997;15:1680-1689.

14. Goodwin JS, Samet JM, Hunt WC. Determinants of survival in older cancer patients. JNCI 1996;88(15):1031-81.

15. Stavraky KM, Skillings JR, Stitt LW et al. The effect of socioeconomic status on the long-term outcome of cancer. J Clin Epid 1996;49(10):1155-1160.

16. Dale W, Vijayakumar S, Lawlor EF et al. Prostate cancer, race, and socioeconomic status: inadequate adjustment for social factors in assessing racial differences. Prostate 1996;29(5):271-281.

17. Greenwald HP, Borgatta EF, McCorkle R et al. Explaining reduced cancer survival among the disadvantaged. Milbank $Q$ 1996;72(2):215-238.

18. Bouchardy C, Fioretta G, DePerrot M et al. Determinants of long term survival. Cancer 1999;86:2229-2237.

19. Robbins AS, Yin D, Parikh-Patel A. Differences in prognostic factors and survival among White men and Black men with prostate cancer, California, 1995-2004. Am J Epidemiol 2007;166:71-78.
20. Reyes-Ortiz CA, Goodwin JS, Freeman JL. The effect of socioeconomic factors on incidence, stage at diagnosis and survival of cutaneous melanoma. Med Sci Monit 2005; 11(5):RA163-172.

21. Lehto US, Ojanen M, Dyba T et al. Baseline psychosocial predictors of survival in localized breast cancer. BJC 2006;94:1245-1252.

22. Dejardin O, Remontet L, Bouvier AM et al. Socioeconomic and geographic determinants of survival of patients with digestive cancer in France. BJC 2006;95:944-949.

23. Abou-Jawde RM, Baz R, Walker E et al. The role of race, socioeconomic status, and distance traveled on the outcome of African-American patients with multiple myeloma. Haematologica 2006;91(10):1410-1431.

24. Coker AL, Du XL, Fang S. Socioeconomic status and cervical cancer survival among older women: findings from the SEER-Medicare linked data cohorts. Gynecol Oncol 2006; 102:278-284.

25. Kaffashian F, Godward S, Davies T et al. Socioeconomic effects on breast cancer survival: proportion attributable to stage and morphology. BJC 2003;89:1693-1696.

26. Bouchardy C, Verkooijen HM, Fioretta G. Social class is an important and independent prognostic factor of breast cancer mortality. Int J Cancer 2006;119:114-1151.

27. Dalton SO, Ross L, During M et al. Influence of socioeconomic factors on survival after breast cancer-a nationwide cohort study of women diagnosed with breast cancer in Denmark 1983-1999. Int J Cancer 2007;121:2524-2531.

28. Thomson CS, Hole DJ, Twelves CJ et al. Prognostic factors in women with breast cancer: distribution by socioeconomic status and effect on differences in survival. J Epidemiol Community Health 2001;55:308-315.

29. Menvielle G, Leclerc A, Chastang JF et al. Social inequalities in breast cancer mortality among French women: disappearing educational disparities from 1968 to 1996 . BJC 2006;94:152-155.

30. Albano JD, Ward E, Jemal A et al. Cancer mortality in the United States by education and race. JNCI 2007; 99:1384-94.

31. Gordon NH. Socioeconomic factors and breast cancer in black and white Americans. Cancer and Metastasis 2003; 22:55-64.

32. Gordon NH, Crowe JP, Brumberg DJ et al. Socioeconomicfactors and race in breast cancer recurrence and survival. $\mathrm{Am}$ J Epidemiol 1992;6:609-618.

33. Cella DF, Orav EJ, Kornblith $\mathrm{AB}$ et al. Socioeconomic status and cancer survival. JCO 1991;9:1500-1509.

34. Herndon JE II, Kornblith AB, Holland JC et al. Patient education level as a predictor of survival in lung cancer clinical trials. JCO 2008;26:4116-4123.

35. Holland JC, Herndon J, Kornblith $\mathrm{AB}$ et al. A sociodemographic data collection model for cooperative clinical trials. PASCO 1992;11:157. Abstract 445.

36. Abrams J, Aisner J, Cirrincione C et al. Dose-response trial of megestrol acetate in advanced breast cancer: Cancer and Leukemia Group B Phase III study 8741. JCO 1999;17:64-73.

37. Kornblith AB, Hollis DR, Zuckerman E et al. Effect of megestrol acetate upon quality of life in a dose response trial with advanced breast cancer patients. JCO 1993; 11:2081-2089.

38. Peters WP, Rosner GL, Vredenburgh JJ et al. Prospective, randomized comparison of high-dose chemotherapy with stem-cell support versus intermediate-dose chemotherapy after surgery and adjuvant chemotherapy in women with high-risk primary breast cancer: a report of CALGB 9082 , SWOG 9114, and NCIC MA-13. JCO 2005;23:2191-2200.

39. Peppercorn J, Herndon J II, Kornblith AB et al. Quality of life among patients with stage II and III breast carcinoma randomized to receive high-dose chemotherapy with autologous bone marrow support or intermediate-dose chemotherapy: results from Cancer and Leukemia Group B 9066. Cancer 2005;104:1580-9. 
40. Parnes HL, Cirrincione C, Aisner J et al. Phase III study of cyclophosphamide, doxorubicin, and fluorouracil (CAF) plus leucovorin versus CAF for metastatic breast cancer: Cancer and Leukemia Group B 9140. JCO 2003;21: 1819-1824.

41. Liu MC, Demetri GD, Berry DA et al. Dose-escalation of filgrastim does not improve efficacy: clinical tolerability and long-term follow-up on CALGB study 9141 adjuvant chemotherapy for node-positive breast cancer patients using doseintensified doxorubicin plus cyclophosphamide followed by paclitaxel. Cancer Treatment Review 2008;34:223-230.

42. Levine EG, Cirrincione CT, Szatrowski TP et al. Phase II trial of topotecan in advanced breast cancer: a Cancer and Leukemia Group B study. American JCO 1999;22(3): 218-222.

43. Winer EP, Berry DA, Woolf S et al. Failure of higher-dose paclitaxel to improve outcome in patients with metastatic breast cancer: Cancer and Leukemia Group B trial 9342. JCO 2004;22(11):2061-2068.

44. Hughes KS, Schnaper LA, Berry D et al. Lumpectomy plus tamoxifen with or without irradiation in women 70 years of age or older with early breast cancer. NEJM 2004:351:971-7.

45. Henderson IC, Berry DA, Demetri GD et al. Improved outcomes from adding sequential paclitaxel but not from escalating doxorubicin dose in an adjuvant chemotherapy regimen for patients with node-positive primary breast cancer. JCO 2003;21:976-983.

46. Citron ML, Berry DA, Cirrincione $\mathrm{C}$ et al. Randomized trial of dose-dense versus conventionally scheduled and sequential versus concurrent combination chemotherapy as postoperative adjuvant treatment of node-positive primary breast cancer: first report of intergroup trial C9741/Cancer and Leukemia Group B trial 9741. JCO 2003;21:1431-1439.

47. Seidman AD, Berry D, Cirrincione $\mathrm{C}$ et al. Randomized phase III trial of weekly compared with every-3-weeks paclitaxel for metastatic breast cancer, with trastuzumab for all HER-2 overexpressors and random assignment to trastuzumab or not in HER-2 nonoverexpressors: final results of Cancer and Leukemia Group B protocol 9840. JCO 2008;26:1642-1649.

48. Kaplan EL, Meier P. Nonparametric estimation from incomplete observations. JASA 1958;53:457-481.

49. Brookmeyer R, Crowley J. A confidence interval for the median survival time. Biometrics 1982;38:29-41.
50. Hosmer DW, Lemeshow S. Applied Survival Analysis. John Wiley \& Sons, 1999.

51. Cox DR. Regression models and life tables (with discussion). JRSS-B 1972;34:187-220.

52. Meara ER, Richards S, Cutler DM. The gap gets bigger: changes in mortality and life expectancy, by education, 1981-2000. Health Aff 2008;27:350-360.

53. Hahn KME, Bondy ML, Selvan M et al. Factors associated with advanced disease stage at diagnosis in a populationbased study of patients with newly diagnosed breast cancer. AJE 2007;166:1035-1044.

54. McCarthy EP, Burns RB, Coughlin SS et al. Mammography use helps to explain differences in breast cancer stage at diagnosis between older black and white women. Ann Intern Med 1998;128:729-736.

55. Li DI, Malone KE, Daling JR. Differences in breast cancer stage, treatment, and survival by race and ethnicity. Arch Intern Med 2003;163:49-56.

56. Gorin SS, Heck JE, Cheng B et al. Delays in breast cancer diagnosis and treatment by racial/ethnic group. Arch Intern Med 2006;166:224-2252.

57. Dailey AB, Kasl SV, Holford TR et al. Neighborhood-level socioeconomic predictors of nonadherence to mammography screening guidelines. Cancer Epidemiol Biomarkers Prev 2007; 16:2293-2303.

58. Newman LA, Griffith KA, Jatoi I et al. Meta-analysis of survival in African American and white American patients with breast cancer: ethnicity compared with socioeconomic status. JCO 2006;24:1342-1349.

59. Albain KS, Unger JM, Crowley JJ et al. Racial disparities in cancer survival among randomized clinical trials patients of the Southwest Oncology Group. JNCI 2009;101:984-992.

60. Polite BN, Cirrincione C, Fleming GF et al. Racial differences in clinical outcomes from metastatic breast cancer: a pooled analysis of CALGB 9342 and 9840-Cancer and Leukemia Group B. JCO 2008;26(16):2659-2664.

61. Blackstock AW, Herndon JE II, Paskett ED et al. Outcomes among African-American/non-African-American patients with advanced non-small-cell carcinoma: report from the Cancer and Leukemia Group B, JNCI 2002;94:284-90.

62. Blackstock AW, Herndon JE II, Paskett ED et al. Similar outcomes between African American and non-African American patients with extensive-stage small-cell lung carcinoma: report from the Cancer and Leukemia Group B. JCO 2006;24(3):407-412. 